LBL-28691

\title{
Hydrogen in Semiconductors
}

\author{
Eugene E. HALLER
}

\author{
University of California at Berkeley \\ and \\ Materials Sciences Division \\ Lawrence Berkeley Laboratory \\ 1 Cyclotron Road \\ Berkeley, California 94720 USA
}

This work was supported in part by the U.S. National Science Foundation under Contract DMR-88-06756 and in part by the Director, Office of Energy Research, Office of Basic Energy Sciences, Materials Science Division of the U.S. Department of Energy under Contract No. DE-AC03-76SF00098.

\section{MHSTER}




\title{
HYDROGEN IN SEMICONDUCTORS
}

\author{
EUGENE E. HALLER \\ Lawrence Berkeley Laboratory \\ and \\ University of California at Berkeley \\ Berkeley, California 94720 USA
}

\section{Introduction}

After an "incubation" period in the 1970's and early 80's, during which the first hydrogen related centers were discovered and characterized in ultra-pure germanium, ${ }^{1-4}$ a rharp increase of research activity occurred after the discovery of shallow acceptor passivation in crystalline silicon. ${ }^{5-7}$ The aim of this review is to convey an insight into the rich, multifaceted physics and materials science which has emerged from the vast variety of experimental and theoretical studies of hydrogen in semiconductors. In order to arrive at the current understanding of hydrogen related phenomena in a logical way, each chapter will start with a' brief review of the major experimental and theoretical advances of the past few years. Those who are interested to learn more about this fascinating area of semiconductor research are referred to reviews, 8,9 to a number of conference proceedings volumes, ${ }^{10}$ and to an upcoming book ${ }^{11}$ which will contain authoritative chapters on most aspects of hydrogen in crystalline semiconductors. Some of the early art of semiconductor device processing can finally be put on a scientific foundation and new ways of arriving at advanced device structures begin to use what we have learned from the basic studies of hydrogen in semiconductors. 12

\section{Hydrogen Containing Complexes}

\subsection{Neutral shallow acceptor-and donor-hydrogen complexes}

Perhaps the greatest impetus for the rise in interest in hydrogen in semiconductors came from the discovery of the deactivation of acceptors near the $\mathrm{Si}-\mathrm{SiO}_{2}$ interface in MOS structures by Sah et al. 5 followed by the direct hydrogen plasma exposure experiments of Pankove et al. 6,7 Hydrogen was implicated by both groups as the cause for the removal of free holes in the p-type silicon. Secondary ion mass spectrometry (SIMS) of deuterium RF plasma exposed p-type silicon wafers showed that the acceptor and the deuterium concentrations were identical in the deactivated region. ${ }^{13}$ The deactivation of acceptors by another impurity immediately reminds us of the well known lithium compensation and passivation of acceptors in Si and Ge. ${ }^{14}$ The fact that one did not observe donors compensating acceptors but the formation of neutral acceptorhydrogen complexes was established through a series of elegant far infrared local vibrational mode (LVM) spectroscopy experiments by Stavola et al. ${ }^{15}$ The strong dependence of the hydrogen stretch vibration frequency on the mass of the acceptor clearly indicates that hydrogen is bound directly to the acceptor. The ratio of hydrogen and deuterium LVM frequencies lies close to $\sqrt{2}$, establishing the observation of a single vibrating hydrogen atom. The fact that the frequency ratio is not precisely equal to $\sqrt{2}$ is related in most cases to the reduced mass of the complete set of atoms involved in the local vibration. Newman 16 interprets the deviation from $\sqrt{2}$ for the $\mathrm{Sn}-\mathrm{H}$ and $\mathrm{Sn}-\mathrm{D}$ stretch vibrations in $\mathrm{GaAs}$ with anharmonicity of the vibrational mode. 


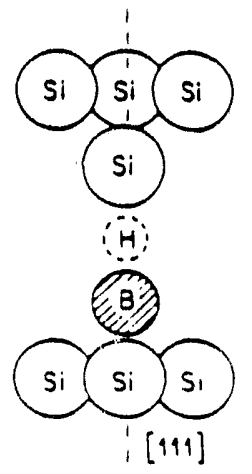

Fig. 1. BC configuration of the B-H complex in Si. (From Ref. 19)

Ion beam channeling, making use of specific nuclear reactions, established the precise location of the passivated boron acceptor ${ }^{17}$ and of the hydrogen bound near a bond center (BC) position. 18 Uniaxial stress LVM spectroscopy by Bergman et al. ${ }^{19}$ unambiguously showed the acceptorhydrogen complexes to have trigunal symmetry (Fig. 1).

Theoretical efforts have been successful in explaining, and in some cases in predicting, the experimental findings. The hydrogen stretch vibration frequency $\left(v_{\text {stretch }}=1875 \mathrm{~cm}^{-1}\right)$ of the $\mathrm{B}-\mathrm{H}$ complex in $\mathrm{i}$ was reproduced by DeLeo and Fowler ${ }^{20}$ who also predicted the LVM frequency of the Al-H center $\left(v_{\text {stretch }}=2201 \mathrm{~cm}^{-1}\right)$ with excellent accuracy. Several calculations lend strong support to the trigonal acceptorhydrogen complex model with a proton $\left(\mathrm{H}^{+}\right)$residing near a bond center (BC) site in one of the four acceptor bonds $21-24$ and we may safely conclude that this model is definitive.

This does not mean, however, that all the details are understood. The Al- $\mathrm{H}$ and Ga-H LVM spectra in Si show low energy sidebands whose origins are still not fully understood. ${ }^{15} \mathrm{~A}$ further problem is related to the absence of wagging modes of the acceptor-hydrogen complexes. Such vibrations have not been found in the expected frequency range between 600 and $800 \mathrm{~cm}^{-1}$. Pajot et al. 25 discovered an unusual difference between the effect of the substitution of $10 \mathrm{~B}$ with $11 \mathrm{~B}$ on the hydrogen and deuterium stretch vibrations. The D stretch frequency shifts by $3.3 \mathrm{~cm}^{-1}$, whereas the $\mathrm{H}$ frequency moves only by $0.8 \mathrm{~cm}^{-1}$. Watkins

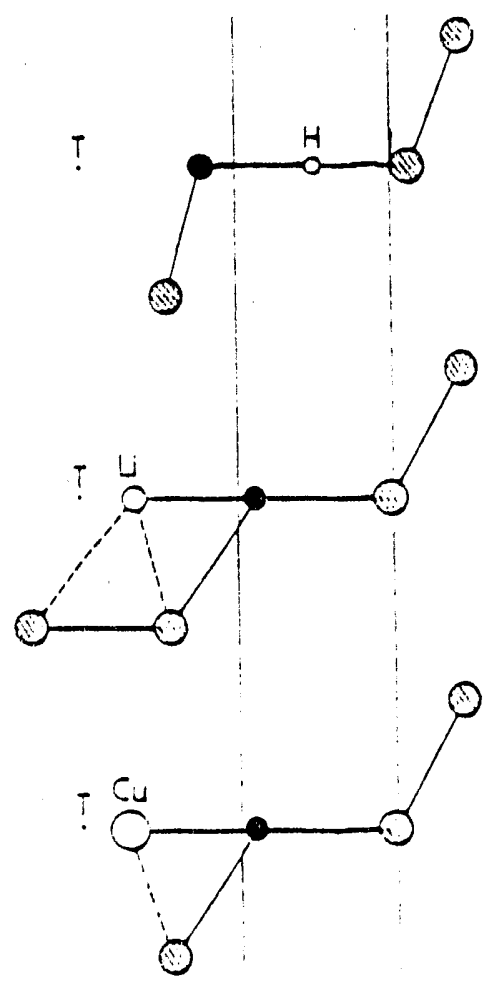

Fig. 2. Fraction of the $\{110\}$ plane showing the lowest-energy configurations of the $\{\mathrm{H}, \mathrm{B}\},(\mathrm{Li}, \mathrm{B})$, and $(\mathrm{Cu}, \mathrm{B}\}$ pairs in $\mathrm{c}-\mathrm{Si}$. (From Ref. 24) et al. 26 have recently proposed an explanation of this difference on the basis of a Fermi resonance.

In closing the discussion on acceptorhydrogen complexes in p-type $\mathrm{Si}$, I would like to draw the reader's attention to an informative theoretical comparison of the structures of boron in Si compensated by hydrogen, lithium and copper. Calculations by Estreicher 27 show the stable position for $\mathrm{H}^{+}$to be $\mathrm{BC}$ while $\mathrm{Li}^{+}$ and $\mathrm{Cu}^{+}$occupy an antibonding (AB) site (Fig. 2). This work was stimulated not only by the hydrogen related findings but also in part by the well established passivation of acceptors by $\mathrm{Li} ;{ }^{14}$ an effect which had been used extensively for many years in the fabrication of large volume lithium drifted germanium gamma ray detectors ${ }^{28}$ and lithium drifted Si X-ray and particle detectors, 29 and by the very recent observation that boron and other shallow acceptors are passivated in Si by polishing wafers. ${ }^{30}$ The theoretical findings together with perturbed angular correlation (PAC) position decay experiments ${ }^{31}$ and additional experimental evidence 32 show that polishing related passivation is not hydrogen related but most likely due to rapidly diffusing interstitial copper. 
Deactivation of shallow donors was discovered in Si by Johnson et al. 33 Donor passivation escaped experimental observation for several years due in part to the lower degree of passivation, to some difficulties in introducing $\mathrm{H}$ into $\mathrm{n}$-type $\mathrm{Si}$, and to the lower thermal stability of these complexes. Spectroscopic studies by Bergman et al. 19 showed that the $\mathrm{H}$-stretch and wag vibrations have frequencies which are almost donor mass independent. Uniaxial stress measurements produce orientational splittings which are fully consistent with trigonal hydrogen-donor complexes. ${ }^{19}$ These experimental results are supported by model calculations which have improved much over recent years. They strongly suggest that $\mathrm{H}^{-}$binds to a $\mathrm{Si}$ atom in the antibonding position which is in a straight extension of the Si-donor bond (Fig. 3). The recent models can reproduce LVM frequencies with reasonable accuracy. Zhang and Chadi ${ }^{34}$ obtain $v_{\text {stretch }}=1290 \mathrm{~cm}^{-1}$ and $v_{\text {wag }}=715 \mathrm{~cm}^{-1}$, while Denteneer et al. 35 arrive at $v_{\text {stretch }}=1460 \mathrm{~cm}^{-1}$ and $v_{\text {wag }}=740 \mathrm{~cm}^{-1}$, as compared to the experimental values for the P-H complex of $v_{\text {stretch }}=1555 \mathrm{~cm}^{-1}$ and $v_{\text {wag }}=809 \mathrm{~cm}^{-1}$, respectively.

The understanding of hydrogen-acceptor and -donor complexes in $\mathrm{GaAs}, \mathrm{Al}_{\mathrm{x}} \mathrm{Ga}_{1-\mathrm{x}} \mathrm{As}, \mathrm{GaP}$, and InP has also progressed significantly in recent years. Comprehensive reviews have been written by Pajot. 36 Though the studies in III-V semiconductors are less extensive than in Si and mostly limited to LVM spectroscopy, deuterium SIMS, and $\mathrm{C} / \mathrm{V}$ measurements, it has been shown unambiguously that hydrogen can passivate group II acceptors $37,38,39$ and group IV donors and acceptors. $9,40,41,42$ All these centers have

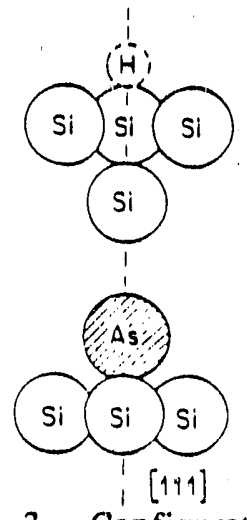

Fig. 3. Configuration of the As- $\mathrm{H}$ complex in $\mathrm{Si}$. (From Ref. 19) trigonal symmetry, as determined by uniaxial stress experiments. 43,44 It $i:$ interesting to note that H-related infrared absorption peaks have been found in bulk InP and in epitaxially grown InP layers which were capped with InGaAs. ${ }^{36}$ In the former case the hydrogen source is traced to wet $\mathrm{B}_{2} \mathrm{O}_{3}$ which acts as an encapsulation layer during crystal growth, while the latter effect can be traced to $\mathrm{AsH}_{3}$ used to grow the capping layer.

From the values of $v_{\text {stretch }}$ and $v_{\text {wag }}$ found in GaAs:Si it has been concluded that hydrogen binds directly to the $\mathrm{Si}_{\mathrm{Ga}}$ donor and lies in an $\mathrm{AB}$ location opposite a broken bond between $\mathrm{SiGa}_{\mathrm{Ga}}$ and one of its As neighbors (Fig. 4). Further evidence comes from
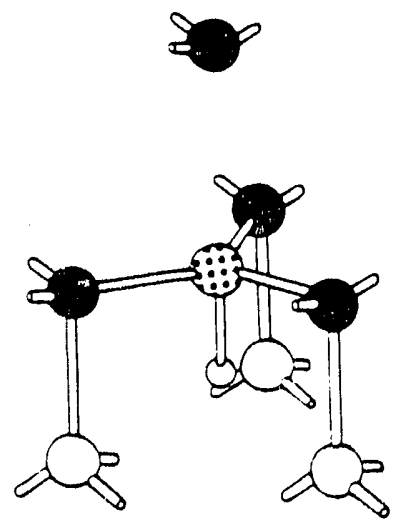

Fig. 4. Configuration of a group IV donor-H complex in GaAs. (From Ref. 36) two small, higher frequency absorp:ion peaks which are assigned to the stable isotopes of ${ }^{29} \mathrm{Si}$ and ${ }^{30} \mathrm{Si}$, both present at concentrations of a few percent in natural silicon. ${ }^{43}$ Both the peak heights and the LVM frequencies support this assignment. Arsenic forms three bonds and has a lone electron pair, a configuration which is common for this group V element. Similar observations have been made for $\mathrm{Sn}_{\mathrm{Ga}}$ donors. $A b$ initio calculations support the $\mathrm{AB}$ site for an $\mathrm{H}^{-}$compensating the donor. 45

Ultra-pure germanium crystals which are $\mathrm{H}_{2}$ atmosphere grown exhibit a strong radial netdopant gradient, often called "coring", 46 which has been explained with the passivation of residual shallow acceptors by hydrogen. 


\subsection{Partially passivated centers}

Multivalent dopants, e.g. double acceptors, can be partially passivated under appropriate circumstances. For a double acceptor this means that one of the negative core charges is screened by a nearby proton while the second core charge still binds a hole. The proton effectively reduces the two acceptor levels of the double acceptor to one level which is typically shallower than either of the levels of the isolated double acceptor. A number of such centers have been studied in Si and in Ge. An interesting facet of these centers is the possibility of studying the symmetry of the structure via optically induced ground state to bound excited state transitions of the remaining hole.

Far infrared Fourier transform spectroscopy has produced high resolution spectra of the acceptors $\mathrm{A}(\mathrm{Be}, \mathrm{H})$ and $\mathrm{A}(\mathrm{Zn}, \mathrm{H})$ in $\mathrm{Ge} 47,48,49$ and $\mathrm{A}(\mathrm{Be}, \mathrm{H})$ in $\mathrm{Si} .50,51$ The latter exhibits a spectrum which has been interpreted with tunneling hydrogen. Recent spectroscopic studies of zinc in hydrogen or deuterium containing silicon samples by Merk et al. ${ }^{52}$ give strong indications that a single acceptor $\mathrm{A}(\mathrm{Zn}, \mathrm{H})$ exists.

The dipole formed between the negatively charged double acceptor core and the nearby positive proton $s_{1}$ lits the fourfold degenerate s-like ground state of the remaining hole into two components. Kahn et al. 53 used uniaxial stress spectroscopy to show that these centers have trigonal symmetry. They found it convenient to model the ground state splitting with an equivalent uniaxial stress $S$ at the impurity core. This local stress only affects the s-like states hut leaves p-like bound excited states unchanged. Using this approach, it is very simple to evaluate the effects of external uniaxial stress on the optical transition spectrum.

The concentrations of the acceptors $A(B e, H)$ and $A(\mathrm{Zn}, \mathrm{H})$ amount to about $1 \%$ of the isolated dopant concentration in Ge single crystals grown in a 1 atm $\mathrm{H}_{2}$ ambient. The thermal stability of both centers has been determined using variable temperature Hall effect and annealing. Fig. 5 displays the free hole freeze-out curve of a beryllium doped $\mathrm{Ge}$ single crystal for various annealing cycles. The high temperature section in which the free hole concentration drops from $\sim 10^{15} \mathrm{~cm}^{-3}$ to $\sim 10^{13} \mathrm{~cm}^{-3}$ is due to the freezing out of the $\mathrm{E}_{\mathrm{y}}+25 \mathrm{meV}$ level of $\mathrm{Be}^{\mathrm{o} /-}$

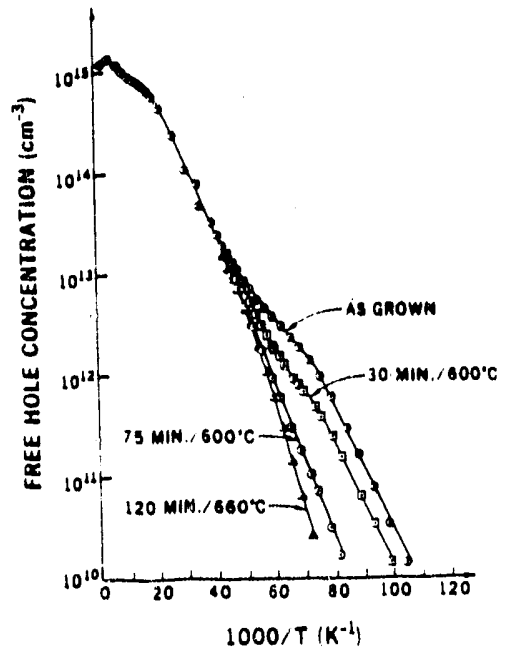

Fig. 5. Free carrier concentration as a function of inverse temperature showing effect of annealing on compensation of shallow levels for Ge:Be. (From Refs. 48,49) $.48,49$ A shallow acceptor with a

concentration close to $\sim 10^{13} \mathrm{~cm}^{-3}$ freezes out at a shallower slope in the "AS GROWN" sample. Spectroscopy shows that this is mainly the acceptor $\mathrm{A}(\mathrm{Be}, \mathrm{H})$. Annealing cycles at temperatures between 600 and $700^{\circ} \mathrm{C}$ are required to break up this complex. Haegel ${ }^{49}$ determined the dissociation energy $E$ and the prefactors $V$ of $A(B e, H)$ and $A(Z n, H)$. She found: $v(\mathrm{~A}(\mathrm{Be}, \mathrm{H}))=3 \times 10^{8} \mathrm{~s}^{-1}$ and $\mathrm{E}(\mathrm{A}(\mathrm{Be}, \mathrm{H}))=2.1 \pm 0.6 \mathrm{eV} ; v(\mathrm{~A}(\mathrm{Zn}, \mathrm{H}))$ $=3 \times 10^{12} \mathrm{~s}^{-1}$ and $\mathrm{E}(\mathrm{A}(\mathrm{Zn}, \mathrm{H}))=3.0 \pm 0.3 \mathrm{eV}$. These values show that the double acceptor-hydrogen complexes in $\mathrm{Ge}$ are bound much more strongly than shallow acceptorhydrogen complexes.

The discussion on partial passivation has been limited to double and triple acceptors in $\mathrm{Si}$ and $\mathrm{Ge}$. To our knowledge no partially passivated double donors have been 
observed. The thoroughly studied chalcogen double donors in Si have so far only been fully passivated. 54 No new shallow donors have been observed which would indicate the formation of a partially passivated single donor complex. Does this mean that these dopants are passivated by two $\mathrm{H}^{-}$or does the presence of one $\mathrm{H}^{-}$push both energy levels out of the forbidden gap? Theoretical guidance would be of great help in answering this question.

\subsection{Activation of neutral impurities by hydrogen}

The first centers in semiconductors which were proven to contain hydrogen were discovered in ultra-pure Ge single crystals after rapid quenching from around $400^{\circ} \mathrm{C} .{ }^{2}$ It was shown that specific crystal growth conditions are necessary to obtain crystals which contain these centers. ${ }^{4}$ The typical ultra-pure $\mathrm{Ge}$ crystal is grown by the Czochralski technique from a melt contained in a silica crucible and in a $\mathrm{H}_{2}$ ambient. The residual netdopant concentration in these crystals can be as low as $10^{10} \mathrm{~cm}^{-3}$ but the neutral impurities $\mathrm{Si}, \mathrm{O}$ and $\mathrm{H}$ are presert at concentrations close to $10^{14} \mathrm{~cm}^{-3}$. At $400^{\circ} \mathrm{C}$ a smiall number of hydrogen atoms become mobile $\left(\mathrm{H}_{2}\right.$ molecules may dissociate) and upon quenching the isolated hydrogen atoms diffuse to shallow potential wells formed by $\mathrm{Si}$ and $\mathrm{O}$. The acceptor $\mathrm{A}(\mathrm{H}, \mathrm{Si})$ and the donor $\mathrm{D}(\mathrm{H}, \mathrm{O})$ which reach concentrations of up to $3 \times 10^{11} \mathrm{~cm}^{-3}$ exhibit a number of interesting properties which will be summarized briefly. The acceptor $\mathrm{A}(\mathrm{H}, \mathrm{C})$ which forms during Ge crystal growth from a graphite crucible has properties which are similar to those of $\mathrm{A}(\mathrm{H}, \mathrm{Si})$.

The acceptors $\mathrm{A}(\mathrm{H}, \mathrm{Si})$ and

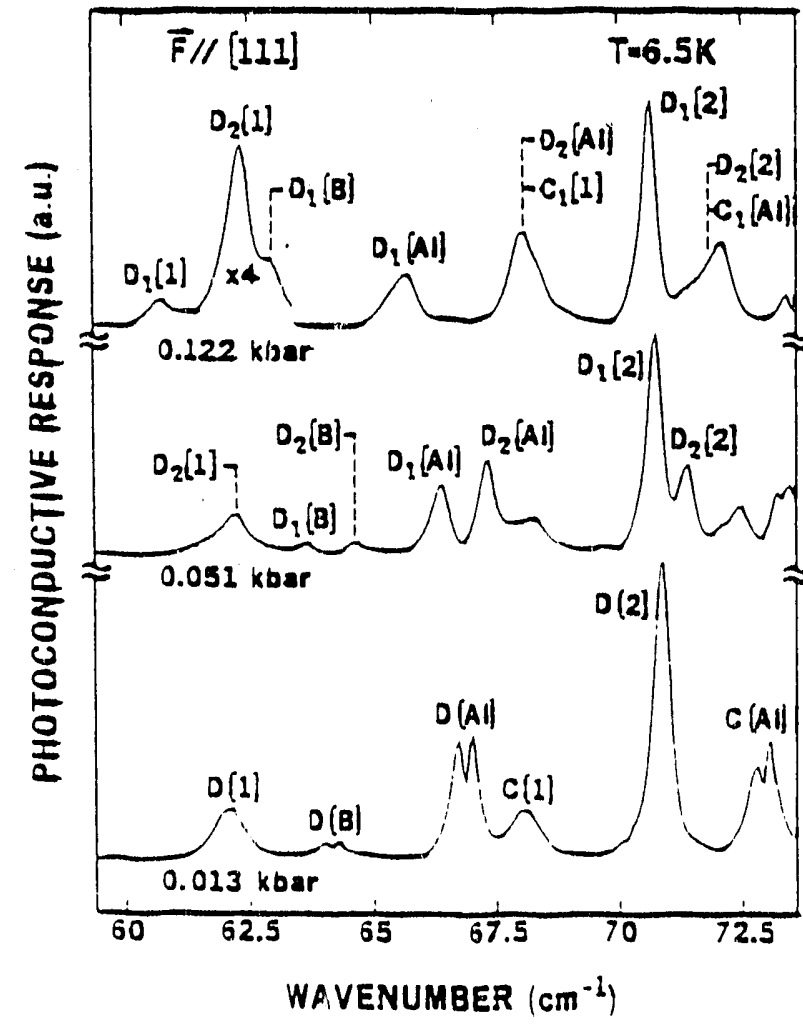

Fig. 6. Far infrared spectra of the $D$ transitions of $\mathrm{A}(\mathrm{H}, \mathrm{Si})_{1}, \mathrm{~A}(\mathrm{H}, \mathrm{Si})_{2}$, and aluminum, under [111] uniaxial compression. In square brackets, the numbers 1 and 2 refer to $A(H, S i) 1$ and $A(H, S i)_{2}$, respectively. (From Ref. 53) $\mathrm{A}(\mathrm{H}, \mathrm{C})$ were the first shallow acceptors in $\mathrm{Ge}$ which exhibited a split 1s-state manifold. ${ }^{4}$ Such a splitting is unusual because the top of the valence band is fourfold degenerate and has $\Gamma_{8}$ symmetry. Kahn et al. ${ }^{53}$ showed that both acceptors aie static complexes which have trigonal symmetry. The splitting can be modeled just as in the case of $\mathrm{A}(\mathrm{Be}, \mathrm{H})$ and $\mathrm{A}(\mathrm{Zn}, \mathrm{H})$ with a local built-in stress which originates from the electric dipole at the core of the complexes. Fig. 6 shows the transitions from the split ground state of the acceptor $\mathrm{A}(\mathrm{H}, \mathrm{Si})$ and the normal shallow acceptor Al for uniaxial compressional stress applied along the [111] orientation. Whereas the $\mathrm{Al} \mathrm{D}$ line splits symmetrically into two components of about equal strength, the $D$ lines of $A(H, S i)$ split in a 1:3 ratio with intensities $3: 1$ as expected for a trigonal complex.

It is interesting to note that the built-in stress $S$ for $A(H, S i)$ has a positive value while the partially passivated $\mathrm{Be}$ and $\mathrm{Zn}$ complexes require a negative $S$. This difference in sign has been explained with the orientations of the internal electric dipole. Calculations of Denteneer et al. 55 showed that $\mathrm{Si}$ in 
Ge indeed binds a $\mathrm{H}^{-}$in an antibonding position.

The 1s-state energies for the trigonal acceptors $\mathrm{A}(\mathrm{H}, \mathrm{Si}), \mathrm{A}(\mathrm{H}, \mathrm{C}), \mathrm{A}(\mathrm{Be}, \mathrm{H})$ and $A(\mathrm{Zn}, \mathrm{H})$ in $\mathrm{Ge}$ have been summarized by Kahn et al. ${ }^{53}$ The average energy of the $1 \mathrm{~s}$ state components lies very close to the ground state energy of $11.2 \mathrm{meV}$ obtained from effective mass theory. 56,57

During annealing of $A(H, S i)$ in rapidly quenched ultra-pure $G e$ a donor $D(H, O)$ forms. 58 Substitution of $\mathrm{H}$ with $\mathrm{D}$ leads to an isotope shift of $51 \mu \mathrm{eV}$, a direct proof of

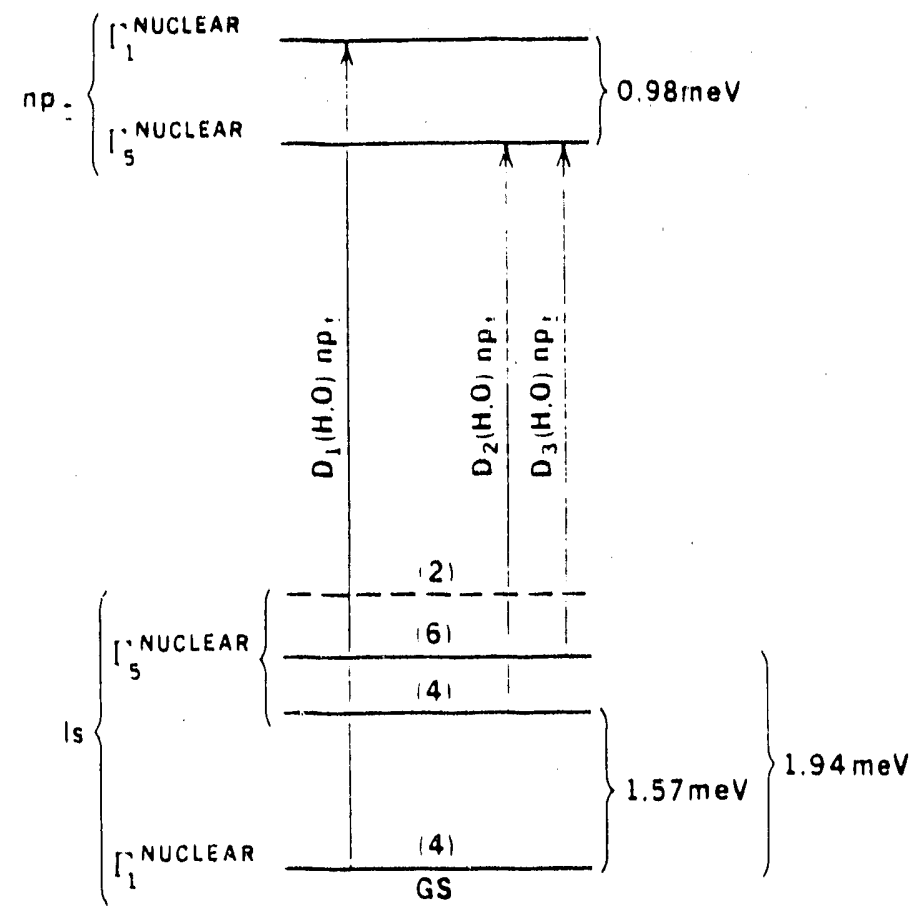

Fig. 7. Schematic total energy level diagram for the donor $\mathrm{D}(\mathrm{H}, \mathrm{O})$ in in $\mathrm{Ge}$ based on the tunneling hydrogen model. (From Ref. 58) the presence of hydrogen in this complex. ${ }^{3}$ The exceptionally sharp lines in the far infrared optical transitions spectrum of $\mathrm{D}(\mathrm{H}, \mathrm{O})$ are due to the fact that the ground- and the bound excited states are stress insensitive and that the crystals are very pure. Navarro et al.59 used this donor for magnetospectroscopic linewidth studies and found that the line broadening approaches closely the ultimate limit given by final state mixing. A second unusual property of $\mathrm{D}(\mathrm{H}, \mathrm{O})$ is the abrupt appearance of a lower energy set of transition lines at a critical uniaxial stress.

Fig. 7 schematically shows an energy level series which accounts for all the experimentally observed splittings and thermal population of higher lying states of $\mathrm{D}(\mathrm{H}, \mathrm{O})$. The nuclear tunneling leads to splitting of the $1 \mathrm{~s}$ - and the np-states. A competing model 60,61 proposed a static, trigonally distorted complex. Both models can explain a majority but not all of the properties of $\mathrm{D}(\mathrm{H}, \mathrm{O})$ and only additional experiments appear to be able to determine which of the two models is the correct one.

The detailed studies of the partially hydrogen passivated and of the hydrogen activated centers could not have been performed without a spectroscopic technique which combines spectral resolution with very high sensitivity. Photothermal ionization spectroscopy (PTIS) which was discovered by Lifshits and Ya'Nad, ${ }^{62}$ relies on a twostep ionization process of an impurity-bound carrier at low temperatures. The first step is the usual optical transition which occurs when an electron (hole) is excited from the groundstate to one of the bound excited states. If the electron (hole) resides in the excited state for a long enough time a phonon may transport it into the conduction band (valence band). In this case the conductivity will change and this change can be detected with modern lock-in techniques with extremely high sensitivity. Grimmeiss et al. ${ }^{63}$ have used PTIS and absorption in the continuum of shallow levels for the study of deep level centers with effective mass-like bound excited states in silicon. Our group has made extensive use of PTIS in the study of residual impurities and defect complexes primarily in ultrapure Ge. ${ }^{4,64}$ 
The major findings from the detailed studies of hydrogen containing complexes are the following:

- Isolated hydrogen is an amphoteric impurity

- Hydrogen can passivate, partially passivate and activate impurities

- Most complexes are static with trigonal symmetry, some are dynamic

- $\mathrm{H}^{+}$resides near a $\mathrm{BC}$ position next to the acceptor it passivates

- $\mathrm{H}^{-}$assumes an $\mathrm{AB}$ position, bound either to the donor directly (e.g. $\mathrm{GaAs}: \mathrm{Si}_{\mathrm{Ga}}, \mathrm{H}$ ) or to one of the host atoms next to the donor (e.g. $\mathrm{Si}: \mathrm{P}, \mathrm{H}$ )

- All the static, partially passivated and activated centers display a $1 \mathrm{~s}$-state splitting which is due to the electric dipole produced between $\mathrm{H}$ and the impurity

- Theoretical models which reproduce most properties with good accuracy exist for most of these complexes

\section{Isolated Hydrogen}

The majority of information on isolated hydrogen has come so far from muon spin resonance ( $\mu S R)$ studies 65 and from theoretical calculations. The study of anomalous muonium $\left(\mathrm{Mu}^{*}\right)$ in semiconductors led Cox and Symons ${ }^{66}$ to propose the $\mathrm{BC}$ site as the most stable pusition for this light hydrogen analogue $\left(\mathrm{m}_{\mathrm{Mu}}=1 / 9 \mathrm{~m}_{\mathrm{H}}\right)$. In the meantime a number of theoretical calculations have arrived at the same conclusion for hydrogen. 67-70 Contour plots for $\mathrm{H}^{+}, \mathrm{H}^{\circ}$, and $\mathrm{H}^{-}$reveal large differences for the low and the high electron density regions. ${ }^{71} \mathrm{H}^{+}$placed at $\mathrm{BC}$ produces a global minimum. The $\mathrm{H}^{+}$at $\mathrm{BC}$ should not be viewed as a bare proton. The missing charge resides in a region near the neighboring $\mathrm{Si}$ atoms and corresponds to the antibonding state in the silicon energy gap. $\mathrm{H}^{\circ}$ also produces a global minimum when placed at $\mathrm{BC}$ though the minimum is less deep than for $\mathrm{H}^{+}$. A very different behavior is observed for $\mathrm{H}^{-}$which prefers the $T_{d}$ site. These calculations describe the static situation at $\mathrm{T}=\mathrm{OK}$ and suggest that hydrogen may be a negative $U$ defect. Each energy value for a given set of coordinates of the energy surfaces is obtained by moving the specific hydrogen charge species infinitesimally slowly to this coordinate and fully relaxing all neighboring silicon atoms. Rapid hydrogen motion which does not allow relaxation of the silicon atoms would lead to very different energy surfaces.

There exists very little experimental information on the states of isolated hydrogen in semiconductors. The obvious search for EPR signals of $\mathrm{H}^{\mathrm{O}}$ remained fruitless until the recent discovery of a signal in low temperature hydrogen implanted silicon. This so-called AA9 spectrum reported by Gorelinski and Nevinnyi 72 displays hyperfine interactions which can be interpreted with hydrogen occupying a BC site. Further information comes from experiments with the hydrogen analogue, muonium. Polarized positive muons $\left(\mu^{+}\right)$ can be implanted, one at a time, into semiconductor crystals. The muon lifetime $(\tau=2.2 \mu \mathrm{s})$ is long enough for them to thermalize and to find a minimum energy position. Kiefl and Estle ${ }^{73}$ have summarized the $\mu$ SR studies in semiconductors. They report that in most semiconductors one observes normal and anomalous muonium. They propose that the anomalous muonium spectrum $\left(\mathrm{Mu}^{*}\right)$ and AA9 EPR signature of hydrogen in silicon are due to isostructural centers of muonium and hydrogen, respectively.

The first direct determination of an energy level of $\mathrm{H}^{\mathrm{O}}+\mathrm{+}$ in $\mathrm{GaAs}$ appears to have been made by Clerjaud et al. ${ }^{74}$ in the study of the formation of carbon-hydrogen complexes. Using local vibrational mode spectroscopy they report that the complexes only form in p-type crystals and have been able to localize the energy level of $\mathrm{Ho}_{+}$near $\mathrm{E}_{\mathrm{v}}+0.5 \mathrm{eV}$. This assignment may only be valid if isolated hydrogen forms a positive $\mathrm{U}$ center, i.e., if the $\mathrm{H}^{-} / \mathrm{o}$ level lies above the $\mathrm{H}^{\mathrm{O}} /+$ level. 
Johnson and Herring ${ }^{75}$ have observed a strong deuterium build-up to large concentrations beyond the depletion layer in a reverse biased, hydrogenated $\mathrm{n}^{+}-\mathrm{p}-\mathrm{Si}$ junction. $\mathrm{H}^{+}$ions drifting through the depletion layers form this large concentration which has been measured as a function of depth by SIMS.

The most important points regarding isolated hydrogen in semiconductors are:

- Theory and experiment find the $\mathrm{BC}$ site to be the stable position for $\mathrm{H}^{+}$and $\mathrm{H}^{\circ}$. This also appears to be the stable position of the anomalous muonium $\left(\mathrm{Mu}^{*}\right)$.

- There exist two charged hydrogen species, $\mathrm{H}^{-}$and $\mathrm{H}^{+}$. The energy levels of $\mathrm{H}^{-10}$ and $\mathrm{H}^{\mathrm{O}}+$ in $\mathrm{Si}$ lie close to the gap center but our present knowledge does not allow us to determine if hydrogen is a negative or a positive $U$ center.

- Evidence of the energy level of $\mathrm{H}^{\mathrm{O} /+}$ in $\mathrm{GaAs}$ near $\mathrm{E}_{\mathrm{v}}+0.5 \mathrm{eV}$.

- $\mathrm{H}_{2}$ molecules may form the bulk of all the hydrogen in a crystal but no experimental proof exists for this assumption.

\section{H Motion}

\subsection{Dynamic complexes}

The shallow acceptor complexes $\mathrm{A}\left(\mathrm{Cu}, \mathrm{H}_{2}\right)$ in $\mathrm{Ge}$ and $\mathrm{A}(\mathrm{Be}, \mathrm{H})$ in $\mathrm{Si}$ and the

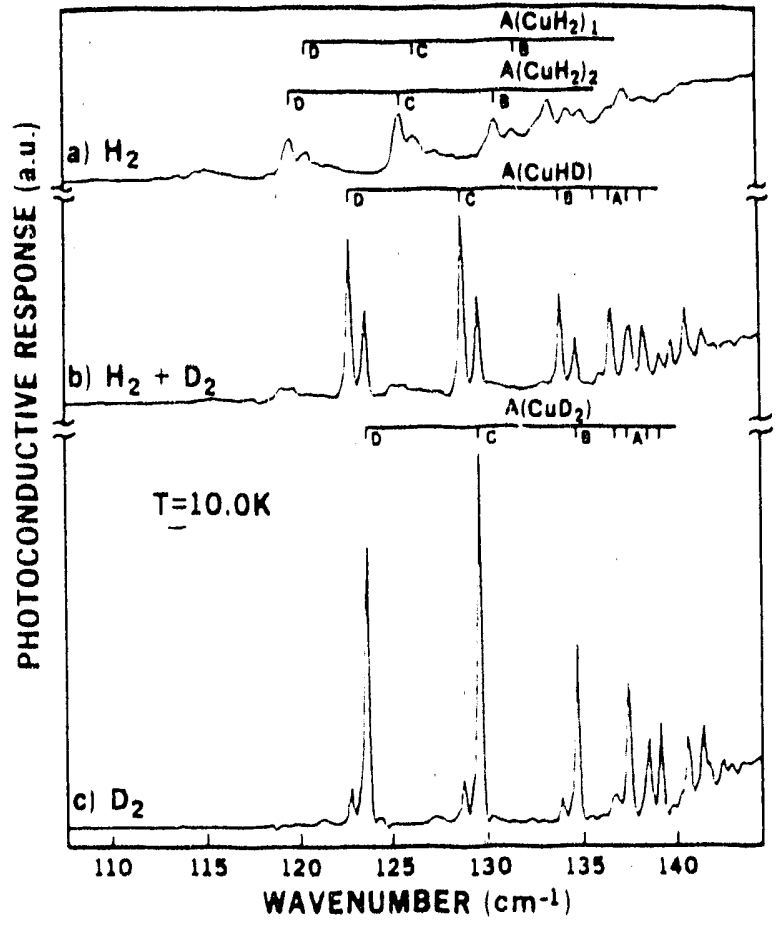

Fig. 8. Photothermal ionization spectra of the copper-dihydrogen acceptors that appear in samples which were grown under atmospheres of different hydrogen isotopes. (a) Pure $\mathrm{H}_{2}$, showing the compiex spectrum of $\mathrm{A}\left(\mathrm{CuH}_{2}\right)$; (b) a 1:1 mixture of $\mathrm{H}_{2}$ and $D_{2}$, showing $\mathrm{A}\left(\mathrm{CuH}_{2}\right), A(\mathrm{CuHD})$, and $A\left(C u D_{2}\right)$ in a $1: 2: 1$ ratio; (c) nearly pure $D_{2}$, showing $\mathrm{A}\left(\mathrm{CuD}_{2}\right)$ and a trace of $\mathrm{A}(\mathrm{CuHD})$. (From Ref. 77) shallow donor $\mathrm{D}(\mathrm{H}, \mathrm{O})$ in $\mathrm{Ge}$ all exhibit special properties which suggest hydrogen to be in a dynamic state. Muro and Sievers 50 and later Peale et al..$^{51}$ used Falicov's tunneling hydrogen model 76 to explain the large isotope shift in the ground state upon substitution of $H$ with $D$ and the $1 \mathrm{~s}$-and np-state splittings of $A(B e, H)$ and $A(B e, D)$ in $\mathrm{Si}$. The analysis of the piezospectroscopy data of $\mathrm{A}(\mathrm{Be}, \mathrm{H})$ and $\mathrm{A}(\mathrm{Be}, \mathrm{D})$ is fully consistent with hydrogen tunneling.

The acceptor $\mathrm{A}\left(\mathrm{Cu}, \mathrm{H}_{2}\right)$ in $\mathrm{Ge}$ is the only center which has been proven to bind two hydrogen atoms. This proof comes from crystals containing both $\mathrm{H}$ and $\mathrm{D}$ leading to three centers when copper is introduced. These are identified as $\mathrm{A}\left(\mathrm{Cu}, \mathrm{H}_{2}\right), \mathrm{A}(\mathrm{Cu}, \mathrm{H}, \mathrm{D})$, and $A\left(C u, D_{2}\right)$ shown in Fig. 8. Kahn et al. 77 analyzed the centers and created further complexes with the radioactive isotope tritium $(T)$. All ihese copper related centers show simple hydrogenic sets of lines except $\mathrm{A}\left(\mathrm{Cu}, \mathrm{H}_{2}\right)$ which has a very complicated 1s manifold with eleven and perhaps more components. Kahn et al. used the Devonshire model of the hindered rotor $^{78}$ to explain qualitatively the 
difference between $\mathrm{A}\left(\mathrm{Cu}, \mathrm{H}_{2}\right)$ and the complexes containing heavier hydrogen isotopes.

The third center which has been modeled using tunneling hydrogen is the shallow donor complex $\mathrm{D}(\mathrm{H}, \mathrm{O})$. Recent magnetospectroscopic studies by Gel'mont et al. ${ }^{79}$ give support to the tunneling model but additional high stress experiments will be required to decide in favor of the static or the dynamic model.

\subsection{Reorientation of the static B-H complex in $\mathrm{Si}$}

At the low temperatures where LVM spectroscopy of the $\mathrm{H}$ passivated acceptors in $\mathrm{Si}$ is performed, the $\mathrm{H}^{+}$is frozen in a $\mathrm{BC}$ position. Dichroism studies by Stavola $e t$ al. 80 derived an activation energy for the randomization of the B-H complexes of $0.19 \mathrm{eV}$ with a prefactor of $\tau_{0} \cong 10^{-11} \mathrm{~s}$. The value of this activation energy is surprisingly close to the energy barrier between two neighboring $\mathrm{BC}$ sites obtained from the static calculations of the total energy surfaces by Denteneer et al..23 Is this close agreement between the experimental result and the static energy barriers accidental? This question belongs to the key issues which have to be resolved before we can claim understanding of hydrogen in semiconductors.

\subsection{Hydrogen diffusion and electric field drift}

The importance of diffusion data is reflected by the fact that the earliest studies of hydrogen in silicon were the permeation experiments by Van Wieringen and Warmoltz ${ }^{82}$ yielding the solubility and diffusion coefficient of $\mathrm{H}$ in $\mathrm{Si}$ at high temperatures. Similar experiments with higher accuracy were performed by Frank and Thomas for Ge. 83 The migration of hydrogen strongly depends on the charge state which in turn depends on the Fermi level position. The static energy surfaces may serve as a guide in understanding the microscopic migration path. The energy barriers along a low energy path are only about $0.2 \mathrm{eV}$, lower than the experimentally determined value at high temperatures.

DeLeo et al..$^{70}$ and Beall Fowler et al..$^{84}$ performed semiempirical calculations which included the relaxation of the silicon host atoms upon motion of $\mathrm{H}^{\circ}$ and $\mathrm{H}^{+}$from one $\mathrm{BC}$ site to another. Their energy barriers for both species are estimated to be $\leq 1 \mathrm{eV}$. These results emphasize the importance of the silicon motion. This is equivalent to thermally activated motion excluding tunneling. In the negative charge state hydrogen prefers the $T_{d}$ site. Migration from $T_{d}$ to $T_{d}$ site requires less $S i$ relaxation and opens the possibility for tunneling.

It should be possible to differentiate between migration of the $\mathrm{H}^{+}$and the $\mathrm{H}^{-}$species with electric field drift experiments. Such experiments have been performed recently by Johnson et al., ${ }^{75}$ Zundel et al., 85 Zhu et al. ${ }^{86}$ and Tavendale et al.87,88 in $\mathrm{Si}$ and by Tavendale et al. ${ }^{89}$ in GaAs. The published results do not yield direct information on the diffusion coefficient of $\mathrm{H}^{-}$because of recombination and dissociation of $\mathrm{H}^{-}$and positively charged donors.

The most sophisticated calculations of high temperature diffusion of $\mathrm{H}^{+}$in Si have been performed by Buda et al. ${ }^{90}$ who used $a b$ initio molecular dynamics simulations. In these calculations the motions of $\mathrm{H}^{+}$and the $\mathrm{Si}$ atoms in a cluster are followed in time steps of $6 \times 10^{-4} \mathrm{ps!}$ In view of the enormous computational effort only high temperature diffusion $\left(\mathrm{T}>1000^{\circ} \mathrm{C}\right.$ ) has been simulated where $\mathrm{H}^{+}$moves over finite distances in a time of 1.5 ps. Close examination of the result of such a calculation shows that $\mathrm{H}^{+}$does not stay on a low energy path. This is due to the large mass ratio between $\mathrm{H}$ and $\mathrm{Si}$. It becomes clear that dynamic or quantum mechanical effects such as zero point vibration, Si relaxation, etc., must be included in theoretical models which shall give an accurate and complete description of $\mathrm{H}$ in semiconductors. Chang and Chadi have investigated hydrogen bonding and diffusion using $a b$ initio self-consistent pseudopotential methods. 91,92 From the comparison of the energy of several hydrogen-impurity and hydrogen-hydrogen complexes they find a new metastable $\mathrm{H}_{2}$ species which is used 
to explain the differences of hydrogen diffusion at low temperatures in n- and p-type silicon.

Blöchl et al. ${ }^{93}$ have used rate theory to calculate the temperature dependent diffusion coefficient of $\mathrm{H}^{+}$in $\mathrm{Si}$ using static total energy surfaces. The results agree to within a factor of three at high temperatures with Buda et al. ${ }^{90}$ calculations and with the experimental results of Van Wieringen and Warmoltz. 82

Hydrogen diffusion affecting the motion of other impurities, in this case oxygen, has been observed by Newman et al.. ${ }^{94,95}$ They report on an enhancement of the rate of oxygen thermal donor formation in $\mathrm{Si}$ catalyzed by hydrogen. The normal oxygen diffusion activation energy of $2.5 \mathrm{eV}$ drops to $\sim 1.5 \mathrm{eV}$ in the temperature range of 250 $-500^{\circ} \mathrm{C}$ in the presence of hydrogen.

The catalysis of enhanced motion of an impurity has been observed some time ago by Hansen et al. 96 who showed that the presence of copper in Ge increases the outdiffusion rate of tritium by large factors. The model for this case of catalyzed motion is based on the dissociation of $\mathrm{H}_{2}$ in $\mathrm{Ge}$ by the formation of transient $\mathrm{Cu}-\mathrm{H}$ species. Finally, work on hydrogen in metals has been in progress for a very long time and we may be able to learn from the work on diffusion of hydrogen in metals which was discussed by Fukai and Sugimoto. ${ }^{97}$

\section{Acknowledgments}

I would like to thank my many friends and colleagues who have collaborated with our group, who stimulated the research with discussion, and who brought important work to my attention.

This work was supported in part by the U.S.-National Science Foundation Contract DMR-88-06756 and in part by the U.S. Department of Energy under Contrast Number DE-AC03-76SF00098.

\section{References}

1. E.E. Haller and W.L. Hansen, Solid State Commun. 15, 687 (1974).

2. R.N. Hall, Inst. Phys. Confr. Ser. 23, 190 (1975).

3. E.E. Haller, Phys. Rev. Lett. 40, 584 (1978).

4. E.E. Haller, W.L. Hansen, and F.S. Goulding, Adv. in Phys. 30, No. 1, 93 (1981)

5. C.T. Sah, J.V.C. Sun and J.J.T. Tzou, Appl. Phys. Lett. 43, 204 (1983); J. Appl. Phys. 54, 437? (1983).

6. J.I. Pankove, D.E. Carison, J.E. Berkeyheiser, and R.O. Wance, Phys. Rev. Lett. 51, 2224 (1983).

7. J.1. Pankove, R.O. Wance, and J.E. Berkeyheiser, Appl. Phys. Lett. A5, 1100 (1984).

8. S.J. Pearton, J.W. Corbett and T.S. Shi, Appl. Phys. A 43, 153 (1987).

9. J. Chevallier and M. Aucouturier, Ann. Rev. Mat. Sci. 18, 219 (1988); Ann. Rev. Inc., Palo Alto.

10. See articles on hydrogen in: Proc. 15 th Int. Confr. on Defects in Semic., Mat. Sci. Forum 38-41 (1989), ed. G. Ferenczi; Proc. 19th Int. Confr. Phys. Semic., ed. W Zawadzki, Inst. of Physics, Polish Ac. of Sci. (1988); Proc. Third Intern. Confr. on Shallow Imp. in Semic.; Inst. Phys. Confr. Ser. 95 (1989); ed. B. Monemar and Mat. Res. Sóc. Proc. Vol. 163 (1990).

11. See articles in "Hydrogen in Semiconducters", eds. J.I. Pankove and N.M. Johnson, Vol. 34 in the "Semiconductors and Semimetals" treatise, Academic Press (1990).

12. E. Constant, N. Caglio, J. Chevallier, and J.C. Pesant, Electron. Lett. 23, 841 (1987).

13. N.M. Johnson and M.D. Moyer, Appl. Phys. Lett. 46, 787 (1985); N.M. Johnson, Phys. Rev. B 31, 5525 (1985).

14. R.H. Pell, J. Appl. Phys. 31, 291 (1960)

15. M. Stavola, S.J. Pearton, J. Lopata, and W.C. Dautremont-Smith, Appl. Phys. Lett. 50, 1086 (1987) and Phys. Rev. B 37, 8313 (1988) 
16. R.C. Newman, Semic. Sci. Techn., accepted for publication.

17. A.D. Marwick, G.S. Oehrlein and N.M. Johnson, Phys. Rev. B 36, 4539 (1987); see also A.D. Marwick, G.S. Oehrlein, J.H. Barrett, and N.M. Johnson, Proc. Mat" Res. Soc. 104, 259 (1988).

18. B. Bech-Nielsen, J.U. Anderson, and S.J. Pearton, Phys. Rev. Lett. 60, 321 (1988); B. Bech-Nielson, Phys. Rev. B 37, 6353 (1988).

19. K. Bergman, M. Stavola, S.J. Pearton, and T. Hayes, Phys. Rev. B 38, 9643 (1988).

20. G.G. Deleo and W.B. Howler, Phys. Rev. B 31, 6861 (1985).

21. A. Amore-Bonapasta, A. Lapiccirella, N. Tomassini, and M. Capizzi, Phys. Rev. B 36, $6228(1987)$.

22. K.J. Chang and D.J. Chadi, Phys. Rev. Lett. 60, 1422 (1988).

23. P.J.H. Denteneer, C.G. Van de Walle, and S.T. Pantelides, Phys. ReV. B 39, 10809 (1989); Phys. Rev. Lett. 62, 1884 (1989).

24. S.K. Estreicher, L. Throckmorton, and D.S. Marynick, Phys. Rev. B 39, 13241 (1989).

25. B. Pajot, A. Chari, M. Aucouturier, M. Astier, and A. Chantre, Solid State Commun. 67, 855 (1988).

26. G.D. Watkins, W.B. Fowler, G.G. DeLeo, M. Stavola, D.M. Kozuch, S.J. Pearton and J. Lopata, Mat. Res. Soc. Proc. Vol. 163, 367 (1990).

27. S.K. Estreicher, Phys. Rev. B 41, 544 (1990).

28. D.W. Freck and J. Wakevield, Nature 4816, 669 (1962),

29. J.T. Walton and E.E. Haller, Mat. Res. Soc. Proc. Vol. 16, 141 (1983).

30. J. Hage, H. Prigge and P. Wagner, Appl. Phys, A 50, 241 (1990).

31. Th. Wichert, R. Keller, M. Deicher, W. Pfeiffer, H. Skudlik, and D. Stiner, Mat. Res. Soc. Proc. Vol. 163, 245 (1990) (MRS Pittsburgh).

32. T. Zundel and J. Weber, Phys. Rev, B 39, 1345 (1989).

33. N.M. Johnson, C. Herring, and D.J. Chadi, Phys. Rev. Lett. 56, 769 (1986).

34. S.B. Zhang and D.J. Chadi, Phys. Rev. B 41, 3882 (1990).

35. P.J.H. Denteneer, C.G. Van de Walle, S. Pantelides, Phys. Rev. B 41, 3885 (1900).

36. B. Pajot, Mat. Res. Soc. Proc. Vol. 163, 465 (1990); see also Inst. Phys. Confr. Ser. 95, 437 (1988).

37. N.M. Johnson, R.D. Burnham, R.A. Street, and R.L. Thornton, Phys. Rev. B 33, $1102(1986)$.

38. B. Pajot, A. Jalil, J. Chevallier, and R. Azoulay, Semicond. Sci. Technol. 2, 305 (1987

39. P.S. Nandhra, R.C. Newman, R. Murray, B. Pajot, J. Chevallier, R.B. Beall, and J.J. Harris, Semicond. Sci. Technol. 3 , 356 (1988).

40. N. Pan, S.S. Bose, M.H. Kim. G.E. Stillman, F. Chambers, G. Devane, C.R. Ito, and M. Feng, Appl. Phys. Lett. 51, 596 (1987).

41. A. Jalil, J. Chevallier, R. Azoulay, and A. Mircea, J. Appl. P'rys. 59, 3774 (1986).

42. N. Pan, B. Lee, S.S. Bose, M.H. Kim, S.J. Hughes, G.E. Stilliman, K. Arai, and Y. Nashimoto, Appl. Phys. Lett. 50, 1832 (1987).

43. B. Pajot, R.C. Newman, R. Murray, A. Jalil, J. Chevallier, and R. Azoulay, Phys. Rev. B 37, 4188 (1988).

44. M. Stavola, S.J. Pearton, J. Lopata, C.R. Abernathy, and K. Bergman, Phys. Rev. $B$ 39, 8051 (1989)

45. P. Briddon and R. Jones, Inst. Phys. Confr. Ser. 95, 459 (1988)

46. W.L. Hansen and E.E. Haller, Mat. Res. Soc. Proc. Vol. 16, 1 (1983).

47. R.E. McMurray, Jr. N.M. Haegel, J.M. Kahn, and E.E. Haller, Sol. State Commun. 61, 27 (1987).

48. T.A. Germer, N.M. Haegel, and E.E. Haller, J. Appl. Phys. 60, 1055 (1986).

49. N.M. Haegel, Ph.D. Thesis UC Berkeley, LBL Report \# 20627 (1985).

50. K. Muro and A.J. Sievers, Phys. Rev. Lett. 57,897 (1986).

51. R.E. Peale, K. Muro, and A.J. Sievers, Phys. Rev. B 41, 5881 (1990).

52. E. Merk. J. Heyman, and E.E. Haller, Sol. State Comm. 72, 851 (1989); see also Mat. Res. Soc. Proc. Vol. 163, 15 (1990).

53. J.M. Kahn, R.E. McMurray, Jr., E.E. Haller, and L.M. Falicov, Phys. Rev. B 36, $8001(1987)$.

54. G. Pensl, G. R.oos, P. Stolz, N.M. Johnson, and C. Holm, Mat. Res. Soc. Proc. Vol. 104, 24 i (1988).

55. P.J.H. Denteneer, C.G. Van de Walle, and S.J. Pantelides, Phys. Rev. Lett. 62 , 1884 (1989). 
56. A. Baldereschi and N. Lipari, Proc. 13th Int. Confr. Phys. Semic., ed. F.G. Fumi (Marves, Rome 1976) p. 595.

57. N. Lipari and A. Baldereschi, Sol. State Comm. 25, 665 (1978).

58. B. Joos, E.E. Haller, and L.M. Falicov, Phys. Rev. B 22, 832 (1980).

59. H. Navarro, E.E. Haller, and F. Keilmann, Phys. Rev. B 37, 10822 (1988).

60. J. Broeckx, P. Clauws, and J. Vennik, J. Phys. C 13, L141 (1980).

61. F.S. Ham ${ }_{y}$ Phys. Rev. B 38, 5474 (1988).

62. T.M. Lifshits and F. Ya Nad, Soviet Phys. Dokl. 10, 532 (1965); for a detailed re view see: Sh. M. Kogan and T.M. Lifshits, Phys. Stat. Sol. (a) 39, 11 (1977).

63. H.G. Grimmeiss, M. Rleverman, and J. Olajos, Proc. 15 th Int. Confr. Defects in Semic., Materials' Science Forim 36-41, 341 (1989).

64. E.E. Hiailer, Festkörperprobleme XXVYVAdy in Solid State Physics 26, 203, ed. P. Grosse (Vieweg, 1986).

65. B.D. Pattersun, Rev. Mod. Phys. 60, 69 (1988).

S6. S.F.J. Cox, M.C.R. Symons, Chem. Phys. Lett. 126, 516 (1986).

67. T.L. Estie, S. Estreicher, and D.S. Marynick, Phys. Rev. Lett. 58, 1547 (1987).

68. P. Deák, L.C. Snyder, and J.W. Corbett, Phys. Rev. B 37, 6887 (1988).

69. C.G. Van de Walle, Y. Bar-Yam, and S.T. Pancelides, Phys. Rev. Lett. 60, 2761 (i988).

70. G.G. DeLeo, M.J. Dorogi and W. Beall Fowler, Phys. Rev. B 38, 7520 (1988).

71. C.G. Van de Walle, P.J.H. Denteneer, Y. Bar-Yam, and S.T. Pantelides, Phys. Rev. B 39, 10791 (1989).

72. Yu. V. Gorelkirskii and N.N. Nevinnyi, Pis'ma Zh. Tekh. Fiz. 13, 105 (1987) Sov. Tech. Phys. Lett. 13, 45].

73. R.F. Kiefl and T.L. Estle, "Muonium in Semiconductors" in Ref. 11.

74. B. Clerjaud, F. Gendron, M. Krause, and W. Ulrici, to be published.

75. N.M. Johnson and C. Herring, Phys. Rev. B 38, 1581 (1988); Proc. 15th Int. Conf. on Defects in Semic., Mat. Sci. Forum 38-41, 961 (1989).

76. E.E. Haller, B. Joć s, and L.M. Falicov, Phys. Rev. B 21, 4729 (1980).

77. J.M. Kahn, L.M. Falicov, and E.E. Haller, Phys. Rev. Lett. 57,2077 (1986).

78. A.F. Devonshire, Proc. R. Soc. London Ser. A 153, 601 (1936).

79. B.L. Gel'mont, V.G. Golubev, V'I. Ivanov-Omski, G.I. Kropotov and E.E. Haller Proc. 19th Intl. Conference Phys. Semic., ed. W. Zawadzki, (J.M. DHM, Ltd., Warsaw, Poland, 1989) p. 1281.

80. M. Atavola, K. Bergman, S.J. Pearton, and J. Lopata, Phys. Rev. Lett. 61, 2786 (1988).

81. M. Stavola, K. Bergman, S.J. Pearton, J. Lopata, and T. Hayes, Inst. Phys. Confr. Ser. 95, 447 (1988).

82. A. Van Wieringen and N. Warmultz, Physica 22, 849 (1956)

83. R.C. Frank and J.E. Thomas, J. Phys. Chem. Solids 16, 144 (1960).

84. W. Beall Fowler, G.G. DeLeo, and M.J. Dorogi, Proc. 15th Int. Confr. on Defects in Semic., Mat. Sci. Forum 38-41, 985 (1989).

85. T. Zundel, E. Courelle, A. Mesli, J.C. Muller, and P. Siffert, Appl. Phys. A 40, 67 (1985).

86. J. Zhu, N.M. Johnson, and C. Herring, Phys. Rev. B $\mathbf{4 1}$ in print.

87. A.J. Tavendale, D. Alexiev, and A.A. Williams, Appl. Phys. Lett. 47, 316 (1985)

88. A.J. Tavendale, S.J. Pearton, and A.A. Williams, Appl. Phys. Lett. 56, 949 (1990).

89. A.J. Tavendale, S.J. Pearton, A.A. Williams, and D. Alexiev, Appl. Phys. Lett. 56, $1457(1990)$.

90. F. Buda, F.L. Chiarotti, R. Car, and M. Parrinello, Proc. 19th Intern. Conf. Phys. of Semic., ed. W. Zawadski, (J.M. DHM, Ltd., Warsaw Poland, 1989) p. 1159.

91. K.J. Chang and D.J. Chadi, Phys. Rev. Lett. 62, 937 (1989).

92. K.J. Chang and D.J. Chadi, Phys. Rev. B 40, 11644 (1989).

93. P.E. Blöchl, C.G. Van de Walle, and S.T. Pantelides, Phys. Rev. Lett. 64, 1401 (1990).

94. R.C. Newman, A.R. Brown, R. Murray, A.K. Tipping, and J.H. Tucker, Proc. 6th Int. Symp. on Silicon Mat. Sci. \& Techn. Semiconductor Silicon 1990 , eds. H.R. Huff, K G. Barraclough and J. Chikawa. (The Electrochemical Soc. 1990) p. 734.

95. R.C. Newman, J.H. Tucker and A.R. Brown, to be published.

96. W.L. Hansen, E.E. Haller, and P. Luke, IEEE Trans. Nucl. Sci. NS-29, No. 1, 738 (1982).

97. Y. Fukai and H. Sugimoto, Adv. in Physics 34, No. 2, 263 (1985). 

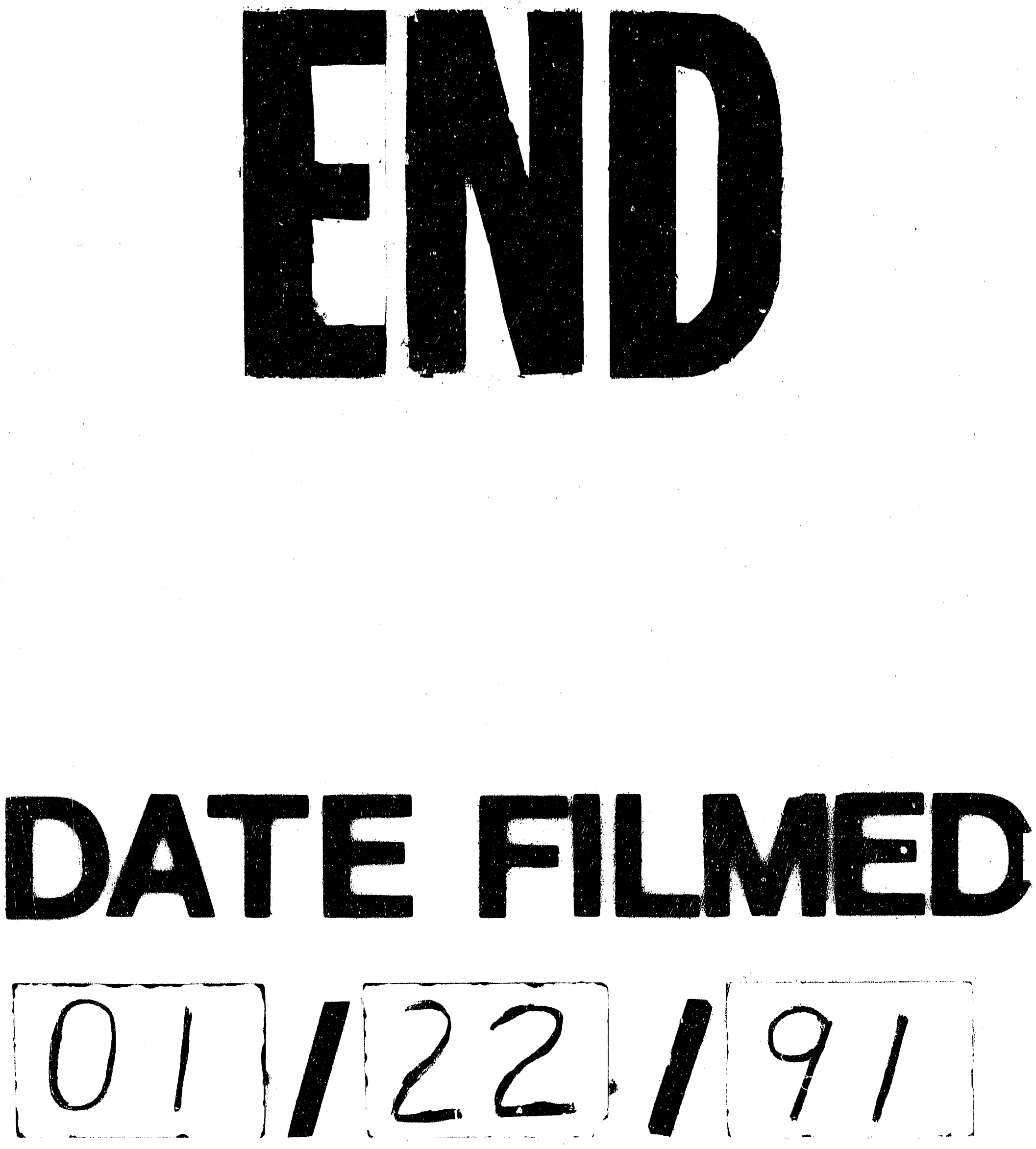
